\title{
Analysis of Market Innovation and Organisational Performance in Nigerian Food and Beverage Manufacturing Sector
}

\author{
${ }^{1}$ Bamidele, Ayodeji Gbenga, ${ }^{2}$ Abdulraheem, Issa (PhD) \& ${ }^{3}$ Brimah, Aminu Nassir (PhD) \\ PhD Candidate, Department of Business and Entrepreneurship, \\ Lecturers, Department of Business and Entrepreneurship \\ School of Business and Governance, \\ College of Humanities, Management and Social Sciences, \\ Kwara State University \\ Malete, Nigeria
}

\begin{abstract}
The study examined the relationship between market innovation and organizational performance. Survey research design was used in the study. Data for this research was obtained from primary sources with the aid of a structured questionnaire. Krejche and Morgan formular was used to estimate the sample size. 355 copies of questionnaires were administered to employees of the selected companies out of which only 309 copies were found to be useful for data analysis. The data were analyzed using descriptive statistics and inferential statistics of partial least square structural equation model (PLS-SEM). The hypothesis was tested at 0.05 alpha levels. Findings revealed that market innovation significantly impacts market performance $(\beta=.317, t=4.720, p=.000)$. The next vital predictor in order of importance is market innovation and employee performance $(\beta=.313, t=4.286, p=.000)$ and finally, market innovation and financial performance $(\beta=.220, t=4.061, p=.000)$. The study concludes market innovation is a key determinant of organizational performance. The study recommended that in order to sustain a competitive edge in today's market; organisations have a twofold mission of continuously generating extra value for their customers whilst thriving to cut costs and increase their productivity. To make this mission possible, the results of this study suggest that organisations give additional importance to market innovations for attaining high organisational performance.
\end{abstract}

Keywords: Innovation, Market, Organisation, Performance, Manufacturing, Industry, Nigeria

Aims Research Journal Reference Format:

Bamidele, A.G. Abdulraheem, I. \& Brimah, A.N. (2019): Analysis of Market Innovation and Organisational Performance in Nigerian Food and Beverage Manufacturing Sector. Advances in Multidisciplinary Research Journal. Vol. 5. No. 1, Pp 23-30.

Article DOI: dx.doi.org/10.22624/AIMS/V5N1P3

Available online at www.aimsjournal.net

\section{INTRODUCTION}

The dynamic nature of business environment and the ever changing needs of consumers have to constantly make strategic organizations to continue to adopt innovative practices to continue to survive. Innovation is a strategic tool for firms to survive and gain competitive advantages in the marketplace. Innovation is the implementation of a new or significantly improved product (good or service), or process, a new marketing method, or a new organizational method in business practices, workplace organization or external relations. Innovation is a process of continuous renewal involving the entire, enterprise and it is an essential part of business strategy. It is also a new way of conveying quality products to customers both consistently and with economic viability in mind. Industry is born out of a need to make a profit. For that it requires innovation to thrive. Indeed the value that innovation brings to an organisation cannot be overstated. Organisation of Economic Cooperation for Development (2005) posits that innovations are central to the growth of output, productivity just as it is a factor of competitiveness. Job and Sanghamitra (2006) argue that innovation benefit companies beyond improved efficiencies or sales growth. 
We can no longer afford relegating creativity and innovation solely to the 'creative industries' if we are to adjust and thrive in a global market. Creativity requires the development of specific organisational capabilities which deviates from the existing ones. Anderson and Markides (2006) state that for competitive advantage, there is need to come up with a differentiated strategy. As such, thinking 'out of the box' has become a recurrent mandate from enlightened shareholders. There has been increasing pressures on organisational stakeholders, from both strategic to operational levels to be creative and innovative with their contributory solutions. However, the challenge with creativity and innovation is that you cannot mandate innovation on, or squeeze it out of employees.

Successful organisations have to make their mark by introducing products or services with particular emphasis on radically diverse value propositions or the adoption of radically different value chain configurations (Kenny \& Reedy, 2007). Although globalisation has created inherent opportunities in terms of access to supply chains and new markets, it has also intensified competition. Vulnerable as the Zimbabwean economy is, operating in a competitive global environment exerts heavy costs. It is especially so, where productivity, technology, efficiencies, cost platforms and quality standards are appalling in comparison to regional and international ones. But to compete effectively organisations need to innovate successfully. The key to competitiveness no longer lies in re-applying past successes or the traditional 'way of doing business' but in fostering organisational capacity for tolerance and the competencies required to nurture creativity and contain the ambiguities and uncertainties that innovation brings. The turbulent nature of the environment which organisations operate has made it a requirement for organisations to compete through introduction and implementation of innovation and adaptability and not neglecting. Firms compete successfully when they offer new, better products and services. In order to harness a competitive edge in the industry they are. Competitive advantage derives from the ability to do and make things better.Drucker (2001) opined that there is only one valid definition of business purpose: to create a customer. It is the customer who determines what the business is, thus, its purpose is to create a customer. Business enterprises have two basic functions, marketing and innovation. According to Johne (1999), market innovation deals with the market mix and market selection in order to meet a customer's buying preference.

Continual market innovation needs to be done by a firm because state-of-the-art marketing tools, particularly through the Internet, make it possible for other competitors to reach potential customers across the globe at a light speed. Market innovation plays a crucial role in fulfilling market needs and responding to market opportunities. In this respect, any market innovation has to be directed at meeting customers' demand and satisfaction (Appiah-Adu \& Satyendra, 1998). Market innovation would augment sales through the increasing demand for products, which in turn yields additional profit to innovative firms. The commercial success of any type of innovation depends on how well it meets customers' needs (Rothwell \& Dodgson, 2007). Despite the critical role of customers in the life of organisations, customers are still dissatisfied with some products in the market place because of its inability to meet their expectations.

\section{LITERATURE REVIEW}

\subsection{Conceptual Clarifications}

\section{Innovation}

Innovation is a strategic tool for firms to survive and gain competitive advantages in the global marketplace. Innovative firms can improve their performances, defeat their competitors and provide value to their stakeholders. Innovation is a source of competitive advantage for a firm (Zawislak, Alves, Tello-Gamarra, Barbieux \& Reichert, 2012). According to Oslo Manual (OECD, 2005), an innovation is the implementation of a new or significantly improved product (goods or services), or process, a new marketing method, or a new organisational method in business practices, workplace organisation or external relations. Oslo Manual (OECD, 2005) classified innovation as product innovation, process innovation, marketing innovation and organisational innovation. It links innovation to performance, i.e "the ultimate reason is to improve firm performance, for example by increasing demand or reducing costs 
The early concept of innovation in economic development and entrepreneurship was popularised by Joseph Schumpeter, a German economist. Innovation, in his view, comprises the elements of creativity, research and development (R\&D), new processes, new products or services and advance in technologies (Lumpkin \& Dess, 2001). To Kuratko and Hodgetts (2004), innovation is the creation of new wealth or the alteration and enhancement of existing resources to create new wealth. Innovation is also seen as a process of idea creation, a development of an invention and ultimately the introduction of a new product, process or service to the market (Thornhill, 2006). At present, this concept is adopted in every facet of social lives and activities. This makes the innovation concept to become more multidimensional and intricate.

\section{Marketing Innovation}

Marketing innovation is referred to as innovation in marketing or new marketing techniques $\|$ in the context of strategic organisational behavior and patterns (Robinson and Pearce 1988). In this research, the authors grouped firms by strategic orientation and found that firms focusing on either (a) product innovation, which in their model includes marketing innovation, or (b) brand identification outperformed those firms focusing on either (a) efficiency or (b) top quality service-high price strategies. Marketing innovation is the capacity to re-conceive the existing industry model in ways that create new value for customers, undermine competitors, and produce new wealth for all stakeholders, according to the organisational knowledge literature (Hanvanach, Droge and Calatone 2003). Marketing knowledge is a powerful strategic asset and a prerequisite for marketing innovation.

Marketing innovation is the generation and implementation of new ideas for creating, communicating, and delivering value to customers and managing customer relationships. A marketing innovation is the implementation of a new marketing method involving significant changes in product design or packaging, product placement, product promotion or pricing (OECD Oslo Manual, 2005). Marketing innovations target at addressing customer needs better, opening up new markets, or newly positioning a firm's product on the market with the intention of increasing firm's sales. Marketing innovations are strongly related to pricing strategies, product package design properties, product placement and promotion activities along the lines of four P's of marketing (Kotler, 2006).

According to Johne and Davies (2000) market innovation deals with the market mix and market selection in order to meet a customer's buying preference. Continual market innovation needs to be done by a firm because state-of-the-art marketing tools, particularly through the Internet, make it possible for other competitors to reach potential customers across the globe at a light speed. Market innovation plays a crucial role in fulfilling market needs and responding to market opportunities. In this respect, any market innovation has to be directed at meeting customers' demand and satisfaction (Appiah-Adu and Satyendra, 1998). The importance of market innovation to firm performance, albeit limited, is discussed in the literature, too. A marketing innovation can be easier and cheaper compared to product innovation for a firm. It might help to rejuvenate the firm's position in a market. A firm may penetrate to its market and increase its sales revenues. Marketing innovation is defined as implementing new marketing method that involve significant changes in the packaging, design, placement and product promotion and pricing strategy. The objective of marketing innovation is to increase the sales and market share and opening new markets. Marketing innovation is non technological innovation. Firms bring innovation in their marketing methods to bring efficiency in their business (Polder et al., 2010).

\section{Organisational Performance}

The nature of organisational performance and its measurement has been a topic for both scholars and practitioners since organisations were first formed. How to determine if the efforts of the organisation are being put to their best use and are achieving the desired outcomes is at the heart of several disciplines. Organisational performance can be judged by many different constituencies, resulting in many different interpretations of "successful performance". Each of these perspectives of organisational performance can be argued to be unique. Further, organisations have varying set of unique features of circumstances, making performance measurement essentially situational (Lebans \& Euske, 2006) provide a set of definitions to illustrate the concept of organisational performance 
Drucker (1954) also argued that the ultimate measure of organisational performance is survival. To this end, Drucker proposed eight different performance dimensions that he felt were essential for the survival and prosperity of a firm. These dimensions included (1) market standing relative to the market potential both now and in the future, (2) innovation, (3) productivity, (4) physical and financial resources, (5) profitability sufficient to cover the risk premium for being in business, (6) manager performance and development, (7) worker performance and attitude, and (8) public responsibility. According to Drucker, these eight dimensions are all necessary for the long-term survival of the organisation, which is the ultimate test of performance.

\subsection{Theoretical Review - Theory of Dynamic Capability}

Dynamic capability is a theory of competitive advantage in rapidly changing environments. In organizational theory, dynamic capability is the capability of an organization to purposefully adapt an organization's resource base. The concept was defined by David Teece, Gary Pisano and Amy Shuen, in their 1997 paper Dynamic Capabilities and Strategic Management, as "the firm's ability to integrate, build, and reconfigure internal and external competences to address rapidly changing environments. The theory arose specifically in response to competitive conditions that emerged at the end of the twentieth century. The dynamic capabilities view (DCV) has emerged as an attempt to untangle the complex problem of sustainable competitive advantage in today's dynamic environment (Teece, Pisano \& Shuen, 1997). The underlying assumption is that firms, which are able to sense and then seize new opportunities and, further, reconfigure their resources and capabilities in line with recognized opportunities and environmental change can create and sustain a competitive advantage (Teece, 2012).

The dynamic capabilities view (DCV) has emerged as an attempt to untangle the complex problem of sustainable competitive advantage in today's dynamic environment (Eisenhardt \& Martin, 2000; Teece, Pisano \& Shuen, 1997). The underlying assumption is that firms, which are able to sense and then seize new opportunities and, further, reconfigure their resources and capabilities in line with recognized opportunities and environmental change can create and sustain a competitive advantage. The theory of dynamic capability explains why firms succeed or fail in market competition. Teece (2007) wrote: "The ambition of the dynamic capabilities framework is nothing less than to explain the sources of enterpriselevel competitive advantage over time, and provide guidance to managers for avoiding the zero profit conditions that result when homogeneous firms compete in perfectly competitive markets".

\section{METHODOLOGY}

The study population consists of the staff of selected firms in the Nigerian Food and Beverage Sector and Conglomerate namely Cadbury Nigerian Plc, FlourMills Nigerian Plc, Nestle Nigerian Plc, UACN Nigerian Plc, and Unilever Nigerian Plc). This survey research is mainly based on primary data collected from employees. A sample was drawn from the population because it is almost impossible to survey the entire population, hence; a sample size of three hundred and fifty five (355) respondents constitutes the sample size for questionnaires that were administered to the staff respondents out of which only three hundred and nine (309) were found to be useful. Data collected from the questionnaire were analyzed, summarized, and interpreted accordingly with the aid of descriptive statistical techniques. Structural equation model was used to show the degree of relationship that exists between organizational innovation and organization performance. 


\section{RESULTS AND DISCUSSION}

Table 1: Summary of the Respondents' Demographic Characteristics

\begin{tabular}{|c|c|c|c|}
\hline $\mathbf{S} / \mathbf{N}$ & Items & Frequency & Percentage (\%) \\
\hline \multirow[t]{3}{*}{1} & Sex & & \\
\hline & Male & 198 & 64.1 \\
\hline & Female & 111 & 35.9 \\
\hline \multirow[t]{5}{*}{2} & Age & & \\
\hline & $18-28 y r s$ & 32 & 10.4 \\
\hline & $29-39 y r s$ & 109 & 35.3 \\
\hline & $40-50 y r s$ & 89 & 28.8 \\
\hline & $50 y r s$ and above & 79 & 25.6 \\
\hline \multirow[t]{4}{*}{3} & Marital status & & \\
\hline & Single & 82 & 26.5 \\
\hline & Married & 208 & 67.3 \\
\hline & Others & 19 & 6.1 \\
\hline \multirow[t]{5}{*}{4} & Academic Qualification & & \\
\hline & Secondary & 1 & 0.3 \\
\hline & ND/NCE & 43 & 13.9 \\
\hline & BSc/HND & 153 & 49.5 \\
\hline & Post Graduate & 111 & 35.9 \\
\hline \multirow[t]{5}{*}{5} & Length of Service & & \\
\hline & $1-5 y r s$ & 104 & 33.7 \\
\hline & $6-10$ yrs & 117 & 37.9 \\
\hline & $11-20 y r s$ & 60 & 19.4 \\
\hline & 21 yrs and above & 28 & 9.1 \\
\hline
\end{tabular}

\subsection{Demographic Profile of the Respondents}

The profile of the respondents was analysed using their demographic characteristics in terms of gender, academic qualification, length of service, marital status and age. The detailed analyses are presented below. The descriptive analysis reveals that $26.5 \%$ of the respondents are single, $67.3 \%$ are already married and $6.1 \%$ of the respondents are other categories (such as, widow, separated, widowers). Descriptive statistics also show that the respondents having length of service between 6 - 10years were $33.7 \%$, followed by the range of $1-5$ years, (33.7\%), 11-20 years $(19.4 \%)$, and lastly 21 years and above have $9.1 \%$. Similarly, for the academic qualification of the respondents, the survey revealed that majority of respondents have bachelor degree/higher national diploma amounted to 153(49.5\%), followed by the category of NCE/ND which amounted to $111(35.9 \%)$; next to Ph.D. with the number of $4(13.9 \%)$. 
And SSCE have only respondent. The descriptive analysis reveals that a large percentage of the respondents were male with $198(64.1 \%)$, while the female responds to the questionnaire survey were $111(35.9 \%)$. However, for the age of the respondents, there are 32 respondents $(10.4 \%)$ that were between 18 - 28years. 109 respondents $(35.3 \%)$ that were between 29 - 39years, 89 respondents $(28.8 \%)$ were between 40 - 50years, and lastly, 79 respondents $(24.7 \%)$ were 20 years and above. Table 1 above shows the summary of the demography of the respondents.

\subsection{Research Hypotheses}

Ho: - Market Innovation does not have significant relationship on organizational performance H1a: Market Innovation does not have significant relationship on market performance $\mathrm{H} 1 \mathrm{~b}$ : Market Innovation does not have significant relationship on financial performance H1c: Market Innovation does not have significant relationship on employee performance

Table 2: Results of Hypotheses Testing

\begin{tabular}{|llcccc|}
\hline Hyp. & Relationship & Beta & S.Error & T - value & P -value \\
\hline $\mathbf{H}_{1 \mathbf{a}}$ & Market N -> Market Performance & 0.317 & 0.067 & 4.720 & 0.000 \\
$\mathbf{H}_{1 \mathrm{~b}}$ & Market N -> Financial Performance & 0.220 & 0.054 & 4.061 & 0.000 \\
$\mathbf{H}_{\text {1c }}$ & Market N -> Employee Performance & 0.313 & 0.074 & 4.286 & 0.000 \\
& & & & & \\
\hline
\end{tabular}

Hypothesis 1a predicted that market innovation is related to market performance based on performance. Result revealed a significant positive relationship between market innovation and market performance based on performance $(\beta=0.317, t=4.720, p=0.000)$, supporting Hypothesis $1 \mathrm{a}$.

Hypothesis $1 \mathrm{~b}$ predicted that market innovation is related to financial performance based on performance. Result revealed a significant positive relationship between market innovation and finaicial performance ( $\beta$ $=0.220, t=4.061, p=0.000$ ), therefore, the Hypothesis $1 \mathrm{~b}$ is not supported.

Similarly, in examining the influence of market innovation on employee performance, result indicated that market innovation had a significant relationship with employee performance $(\beta=0.313, t=4.286, p=0.000)$, support Hypothesis 1c. 


\section{CONCLUSION AND RECOMMENDATIONS}

Innovation seen as a strategy that is widely accepted by most organisations in contemporary economies informs the conclusion of this study that innovation, in its various types and degree, is a key determinant of organizational performance across industries. Therefore, every company seeking competitiveness and improved performance should consider the inclusion of appropriate innovation strategies for the realisation of the desired outcomes since the ultimate goal of innovation is to improve business performance. Given that, presently, the business environment is continually changing, market innovation becomes a competitive advantage when it is based on the understanding of customers' needs.

Also, in order to sustain a competitive edge in today's market, organisations have a twofold mission of continuously generating extra value for their customers whilst thriving to cut costs and increase their productivity. To make this mission possible, the results of this study suggest that organisations give additional importance to market innovations for attaining high organisational performance. performance, in form of customer satisfaction, sales and market share, profitability, employee commitment and satisfaction can be enhanced through innovative performance. Hence, it should be given due importance. Findings of this study support the fact that market innovativeness is one of the fundamental ways that an organisation can use to gain sustainable competitive advantage while also enhancing its performance. 


\section{REFERENCES}

1. Appiah-Adu, K. \& Satyendra, S. (1998). Customer Orientation and Performance: A Study of SMEs, Management Decisions, 36 (6): 385-94.

2. Drucker, $P$ (2001). The practice of management. New York: Harper and Row Publishers

3. Hanvanach, Sangphet, Cornelia Droge, and Roger Calatone. Reconceptualizing the meaning and domain of marketing knowledge." Journal of Knowledge Management. 7(4), 1-11

4. Johne, A., and Davies, R. (2000). Innovation in Medium- Sized Insurance Companies: How Marketing Adds Value. International Journal of Bank Marketing, 18(1): 6-14.

5. Lebans, M., Euske, K. (2006), "A conceptual and operational delineation of performance", Business Performance Measurement, Cambridge University Press

6. Lumpkin, G. T. \& Dess, G. G. (1996). Clarifying the Entrepreneurial Orientation Construct and Linking It to Performance," Academy of Management Journal, 21 (1):135- 72.

7. Kenny, B \& Reedy, E (2006). The impact of organisational culture factors on innovation levels in SMEs: An empirical investigation', Irish Journal of Management, 27(2), 119-142.

8. Kotler Philip (2006); Marketing Management; Prentic-Hall of India/Pearson Education, New Delhi

9. Kuratko, D.F., Hodgetts, R.M., (1998). Entrepreneurship: A Contemporary Approach. Dryden Press, Fort Worth.

10. OECD (2005). Oslo Manual: Guidelines for Collecting and Interpreting Innovation Data 3rd Edition. OECD: Paris

11. Polder, M., Leeuwen, G.V., Mohnen, P., \& Raymond, W. (2010). Product, process and organisational innovation: drivers, complementarity and productivity effects: UNUMERIT,Maastricht Economic and Social Research and Training Centre on Innovation and Technology

12. Rothwell, R \& Dodgson, M. (2007). External linkages and innovation in small and medium-sized enterprises, R\&D Management, 21(2): 1-11

13. Robinson, R.B., \& John A. P. (1988): Planned Patterns of Strategic Behavior and their Relationship to Business-Unit Performance. Strategic Management Journal 9(1): 43- 60.

14. Teece D., Pisano G., (1994), 'The dynamic capabilities of firms: an introduction', Industrial and Corporate Change, 3, 537-556

15. Teece D.J., Pisano G., Shuen A., (1997), 'Dynamic capabilities and strategic management', Strategic Management Journal, 18(7), 509-533

16. Thornhill, S. (2006). Knowledge, Innovation and Firm Performance in High- and Low- Technology Regimes, Journal of BusinessVenturing, 21, 687-703.

17. Zawislak, P. A., Alves, A. C., Tello-Gamarra, J., Barbieux, D., Reichert, F. M. (2012) Innovation capability: From technology development to transaction capability. Journal of Technology Management and Innovation. 7 (2), 14-26. 